\title{
Report of the ISNFF-ICoFF 2019 joint conference
}

The joint meeting of the 7th International Conference on Food Factors (ICoFF) and the 12th International Conference and Exhibition on Nutraceuticals and Functional Foods (ISNFF) was held on December 1-5, 2019 in Kobe Japan. This was preceded by the 9th International Conference on Polyphenols and Health (ICPH) from November 28 to December 1, 2019. The meeting attracted some 1,600 participants from 38 countries with numerous oral and poster presentations. The conference, under the initiative of ISNFF, included for the first time a series of flash talks for posters that provided concise overviews of research activities. Journal of Food Bioactives accepts manuscripts from all presenters for publication consideration with applicable fee waiver by referencing the conference and as invited submission. The bioactive area attracted much attention in this event and as it related to health promotion and disease risk reduction were a focal point. The Journal of Food Bioactives will consider appropriate manuscripts for inclusion upon acceptance via the usual process and free of processing charges as invited manuscripts.

The conference included 4 plenary sessions, 58 regular sessions, a pre-conference joint ICPH/ICoFF/ISNFF session, a keynote session, and a special lecture. The topics covered varied and included, but not limited to, the following topics:

- Nutritional challenges and potential health benefits of functional foods, nutraceuticals, and dietary supplements

- Absorption, bioavailability, and metabolism

- Bioactive amino acids and proteins

- Cardiovascular health

- Marine products

- Functional foods and beverages

- Skin health

- Cancer chemoprevention

- Molecular mechanisms

- Metabolic syndrome and diabetes

- Functional proteins and peptide

- Natural plant pigments

- Nutritional regulation of epigenetics

- Omic technologies

- Molecular targets of food factors

- Antioxidants and redox regulation

- Allergy and immune modulation

- Biomarkers

- Phenolics and antioxidants

- Functional carbohydrates

- Fermented foods

- Taste and olfaction

- Collagen peptides

- Exosome and micro RNA

- Probiotics and prebiotics

- Phytonutrients

- Sports and athletic performance
- Human studies and functional food factors

- Functional assessment of food factors

- Herbs and spices

- Bone health and lifestyle

The conference was complemented by an exhibition that provided display of products, services and publication outlets. The luncheon sessions took advantage of the sponsored presentation by companies who could promote their products and highlight their place in the global market.

A number of distinguished ISNFF awards were presented at the gala dinner. Dr. Chi-Tang Ho of Rugters University (New Brunswick, NJ, USA) received the ISNFF Lifetime Achievement Award. ISNFF Fellow awards were presented to Dr. Cesarettin Alasalvar of TÜBİTAK MAM (Gebze, Turkey); Dr. Kazuo Miyashita of Hokkaido University (Hokkaido, Japan); Dr. Colin Barrow of Deakin University (Melbourne, Australia); and Dr. Gow-Chin Yen of National Chung Hsing University (Taichung, Taiwan). Dr. Petras Rimantas Venskutonis of Kaunas University of Technology (Kaunas, Lithuania) received the society Merit Award. Furthermore, the Fereidoon Shahidi Fellowship Award was presented to Tharindu Ruchira Lakni Senadheera of Memorial University (St. John's, NL, Canada).

The Flash Talk Competition was judged, and first through third places were awarded at each of the three flash talk sessions. The First Place winners were Yuqing Wang, China Natl. Res. Inst. of Food and Fermentation Ind. (China); Rawiwan Wongpoomchai, Dept. of Biochem., Fac. Med., Chiang Mai Univ. (Thailand); Func. Food Res. Chen. For Well-Being, Chiang Mai Univ. (Thailand); and Po-Sheng Chang, Dept. of Nutr., Chung Shan Med. Univ. (Taiwan). The Second Place winners were: Tomoko Asai, Dept. of Food Sci. and Nutr., Fac. of Human Life and Environ. Sci., Nara Women's Univ. (Japan); Anayt Ulla, Dept. of Nutr. Physiol., Inst. of Med. Nutr., Tokushima Univ. Grad. Sch. (Japan); and Sachiko Okue, Dept. of App. Life Sci., Grad. Sch. of Bioresour. Sci., Nihon Univ. (Japan). The Third Place winners were: Aroonrat Pharapirom, Dept. of Biochem., Fac. of Med., Chiang Mai Univ. (Thailand); Chih-Chung Wu, Dept. of Food and Nutr., Providence Univ. (Taiwan); Eko Susanto, Dept. of Marine Bioresour. Chem., Grad. Sch. of Fish. Sci., Hokkaido Univ. (Japan), Dept. Fish. Prod. Tech., Fac. Fish. and Marine Sci., Diponegoro Univ. (Indonesia).

The conference was concluded very successfully and the next ISNFF conference was announced to be held on October 18-21, 2020 in Nanjing, China in Hotel Platinum Hangjue. The 8th ICoFF also will be held in 2023 in China, possibly again as a joint meeting with ISNFF. We encourage you to attend these future meetings and engage with the scientific community interested in nutraceuticals and functional foods. Further, please consider joining ISNFF to stay connected with news and these future events. Information is available at the society website: www.isnff.org.

Fereidoon Shahidi and Bradley Bolling 